\title{
Design of a decision support system for multiobjective activity planning and programming using global bacteria optimization
}

\author{
Autores \\ Miguel Angel Jimenez-Barros, Diana Gineth Ramirez Rios, Carlos Julio Ardila Hernandez, \\ Lauren Julieth Castro Bolaño, Dionicio Neira Rodado.
}

\begin{abstract}
The success of any project lies in a great manner on keeping costs in the estimated values, as well as meeting customer required due date. Therefore, there is a current need of developing an information system that facilitates the creation and managing of projects and their processes, including costing schemes, as well as monitoring an optimizing project's makespan. In order to address this situation a user-friendly information system (IS) was developed. This IS includes an optimization module that reduces the project's execution time, thus, minimizing costs and ultimately providing the manager with the right tools for the correct development of the project. Therefore, a better planning of activities in a reduced time is accomplished. In this way, the project manager is equipped with a decision support system (DSS) that allows a better decision making and, thanks to this performance optimization, a cost-effective solution can be delivered to the company. The optimization module is the main innovative component in this IS, considering that addresses the problem as a multiobjective one, considering at the same time makespan and cost. This module is based on global bacteria optimization (GBO). This becomes the most relevant improvement when compared to other ISs in the market.
\end{abstract}

Palabras clave

Information systems, DSS, GBO, Multiobjective optimization, Engineering projects, Project management. 